\title{
Journal of the Georgia Public Health Association
}

Fall 2019

\section{The Impact of Maternal Literacy Skills on Child Weight in Mozambique}

\author{
Author Affiliations \\ Ashley Watson, Georgia State University \\ Shannon Self-Brown, Georgia State University \\ Iris Feinberg, Georgia State University \\ Whitney Rostad, Georgia State University \\ Corresponding Author \\ Ashley Watson (ashley.e.watson@outlook.com)
}

Follow this and additional works at: https://digitalcommons.georgiasouthern.edu/jgpha

Part of the Public Health Commons

\section{Recommended Citation No. 2 , Article 16. \\ DOI: 10.20429/jgpha.2019.070216 \\ Available at: https://digitalcommons.georgiasouthern.edu/jgpha/vol7/iss2/16}

Watson, Ashley; Self-Brown, Shannon; Feinberg, Iris; and Rostad, Whitney (2019) "The Impact of Maternal Literacy Skills on Child Weight in Mozambique," Journal of the Georgia Public Health Association: Vol. 7 :

This original research is brought to you for free and open access by the Journals at Digital Commons@Georgia Southern. It has been accepted for inclusion in Journal of the Georgia Public Health Association by an authorized administrator of Digital Commons@Georgia Southern. For more information, please contact digitalcommons@georgiasouthern.edu. 


\title{
Original Research
}

\section{The Impact of Maternal Literacy Skills on Child Weight in Mozambique}

\author{
Ashley Watson, $\mathrm{MPH}^{1}$, Shannon Self-Brown, $\mathrm{PhD}, \mathrm{MA}^{2}$, Iris Feinberg, PhD, MA, MBA³ and Whitney Rostad, PhD, $\mathrm{MA}^{1}$ \\ ${ }^{1}$ Master of Public Health, School of Public Health, Georgia State University, Atlanta, GA, ${ }^{2}$ National SafeCare Training and Research Center, \\ School of Public Health, Georgia State University, Atlanta, GA, ${ }^{3}$ Adult Literacy Research Center, Georgia State University, Atlanta, GA \\ Corresponding Author: Ashley Watson • 140 Decatur St SE, Atlanta, GA $30303 \bullet 770-827-8591 \bullet$ ashley.e.watson@outlook.com
}

\section{ABSTRACT}

Background: Infant mortality is a serious public health problem. One factor that is strongly associated with infant mortality is low weight in children. The percentage of underweight children under the age of five in Mozambique was 16\% in 2012. In order to reduce the number of underweight children in this country, contributing caregiver characteristics of this problem should be investigated. One potentially relevant characteristic is maternal literacy, which has been under investigated.

Objective: This study aims to determine whether maternal literacy affected the weight and body-mass-index (BMI) of children ages 0 to 3 years old in Mozambique.

Methodology: A cross-sectional study of 6,762 children between the ages of 0 and 47 months was conducted using the 2011 Demographic and Health Survey for Mozambique. Analysis of covariance (ANCOVA) procedures with Scheffe post hoc tests were performed in order to identify differences in mean child weight and BMI Z-score in reference to maternal literacy level, controlling for several covariates (e.g., mother's weight, education). The data were analyzed using Statistical Analysis Software Version 9.4.

Results: In the study sample, 396 (6.05\%) children were found to be underweight and 4467 (58.69\%) of mothers were found to be illiterate. There was a statistically significant association between maternal literacy level and the weight and BMI of children between the ages of 0 and 3 years of age, after controlling for other known predictors. A trend of stronger association was observed for each one-year increase in child age.

Conclusions: Maternal literacy is significantly associated with child weight and BMI. Prioritizing secondary education for women is one important approach for ameliorating the risk of underweight children. Increased literacy rates in women could lead to better understanding of child nutritional needs, and ultimately, an overall reduction in the number of underweight children

Keywords: Literacy, BMI, weight, Mozambique, maternal, infant, mortality

https://doi.org/10.20429/jgpha.2019.070216

\section{INTRODUCTION}

The mortality rate of children under the age of five is relatively high in Mozambique, especially in the rural areas of the country (World Health Organization, 2011). However, rates did significantly decrease nearly $15 \%$ in urban areas and 13\% in rural areas between the years 1997 and 2011. Nonetheless, this statistic remains over 100 deaths per 1,000 live births each year (World Health Organization, 2011).

An important contributing factor to infant mortality is child weight (Vesel et al., 2010). WHO defines underweight as "weight-for-age less than -2 standard deviations of the WHO Child Growth Standards median” (World Health Organization, 2011). The percentage of underweight children in Mozambique is very high, sixteen percent in 2012 (UNICEF, 2013). This is especially apparent when compared to the United States' percentage of underweight children under the age of 5 , which has consistently remained less than one percent since 2007 (World Health Organization, 2011).

Past research has shown that factors such as household wealth and maternal education level at time of infant birth can significantly affect child weight (Mallard et al., 2014). The findings related to household wealth is a common finding in the literature and is not surprising given the financial capacity typically results in food access (Mallard et al., 2014). Consequently, given rural regions are often the poorest, many studies have demonstrated that child weight statistics are often poorer in rural areas (Esposito et al, 2011; Rajalakshmi et al, 2013). Household wealth was found to be significantly associated with the weight-for-height Z-scores of 18 month olds in Zambia (Mallard et al., 2014). Additionally, Makoka \& Masibo (2015) suggested that improved child nutrition status was associated with increased economic status of the family.

In terms of maternal education, prior research exploring factors that lead to young children being underweight have 
commonly examined low rates of maternal education as a major preceding factor (Burchi, 2012; Mallard et al., 2014; Wolde, Berhan, \& Chala, 2015). The proposed pathway for this relationship is that a lack of maternal formal education is associated with a lack of nutrition knowledge, which ultimately leads to poor child nutrition and low child weight. This is imperative to consider in Mozambique, as only five percent of the nation's gross domestic product (GDP) is spent on education. On average, a Mozambican female only spends nine years in school; this is almost half of the amount of time spent in school by American females (Central Intelligence Agency, 2014). Previous research has shown a significant association between maternal education and child nutrition in low resource countries (Makoka and Masibo, 2015; Rajalakshmi, et al., 2013; Wolde et al., 2015). For instance, Makoka and Masibo (2015) found that mothers with more education have a better knowledge of recommended child feeding practices. They also found that educated mothers tend to have fewer children and provide better care for their children in Malawi, Tanzania, and Zimbabwe.

Prior research has also demonstrated an association between maternal education and child height has also been demonstrated in child height (Burchi, 2010; Burchi, 2012; Mallard et al., 2014). Burchi (2010) found that an increase in Mozambique mothers' primary education was found to be directly associated with an increase in nutrition knowledge and children's height-for-age Z-score. Another study found a similar association between maternal years of schooling and a child's height-for-age Z-score, as well as a positive association between schooling and child weight-for-age Zscore (Burchi, 2012). A mother's education was also significantly associated with the weight-for-height Z-scores of 18 month olds in Zambia (Mallard et al., 2014). This could suggest that measures such as BMI, which refers to body-mass-index, takes into account weight and height, are also affected by maternal education. BMI is defined as "weight in kilograms divided by the square of height in meters” (Centers for Disease Control, 2015).

It has been shown that improved understanding of nutrition can be achieved by increasing secondary education among women (Makoka \& Masibo, 2015). Improved nutritional knowledge can affect a child's diet. For example, mothers with increased years of schooling provide a better quality and higher quantity diet to their infants (Wachs, 2008). Likewise, better nutrition knowledge in Mozambican mothers resulted in a more diverse and healthy diet being chosen for their children (Burchi, 2010). Similar findings were observed in Zambia, where increased maternal education was found to predict increased diversity in infant diet at 12 months of age (Mallard et al., 2014). Additionally, a Nigerian study found a significant difference in the number of stunted children under the age of 5 years based on whether their mothers had received any formal education (Sufiyan, Bashir, \& Umar, 2012). Therefore, there is mounting compelling evidence of a strong association between maternal education and child nutrition.
Education is a broad concept that encompasses various skills. However, researchers have observed that literacy is an essential factor for learning. For instance, reading has been shown to improve numeracy and mathematical vocabulary (Young-Loveridge, 2004; Hassinger-Das, Jordan, \& Dyson, 2015). In the study by Hassinger-Das and colleagues, it is demonstrated that learning math vocabulary through storytelling improved children's understanding of words like "more, less and equal." Understanding these abstract concepts is essential for developing mathematical, and numerous other, skills. Researchers also found that children's motor skills were associated with reading proficiency, as well as handwriting skills (Julius, et al., 2016) In Mozambique, an estimated $45.5 \%$ of females over the age of fifteen can read and write., in comparison to 73.3\% of literate Mozambican males (Central Intelligence Agency, 2014). Education and literacy have been found to be positively correlated in Mozambique (Esposito, Kebede, \& Maddox, 2011).

While education level has been commonly explored, very few studies have considered the specific contribution of literacy in the association between this factor and child size. This is the primary purpose of this current paper. For the purposes of this paper, maternal literacy is defined as maternal reading and writing skills. The purpose of the current study is to examine the relationship between maternal literacy and child weight, while controlling for factors that have been found to contribute to child weight in prior research. In order to test this hypothesis, this study will compare child weight amongst different categories of maternal literacy.

\section{METHODS}

The data source for this project was the Demographic and Health Survey (DHS) for the country of Mozambique (IDHS, 2011). Specifically, data from the Women's Questionnaire subset was used for analyses. Procedures and questionnaires were approved by ICF Institutional Review Board in compliance with the U.S. Department of Health and Human Services regulations for the protection of human subjects (45 CFR 46) (The DHS Program, n.d.). Permission to use these data was granted by the Demographic and Health Survey Program. Sampling was done through a stratified two-stage cluster design that involves drawing Enumeration Areas from the country's Census files and sampling households from each area. The data were collected through interviewer-assisted questionnaires, which took place in the subject's home. These questionnaires were administered in the home by DHS field workers and reported by classification, i.e. mothers.

\section{Participants}

A total of 13,745 females between the ages of 15 and 49 were sampled from the population of Mozambique with the goal of obtaining general demographic information. However, for this specific analysis, the data was subset to exclude all females who were not mothers. A female's maternal status was determined by entries in the maternity table, specifically, a record of number of children each 
woman had given birth to in her lifetime. After excluding non-mothers, the sample size was reduced to 7,623 women. The weight of 6,762 children between the ages of 0 and 3 years were included in this analysis. The age distribution of children was as follows: 1210 (17.89\%) between the ages of 0-11 months, 1691 (25.01\%) between the ages of 12-23 months, 1917 (28.35\%) between the ages of 24-35 months, and 1944 (28.75\%) between the ages of 36-47 months.

\section{Measures}

Two dependent variables were investigated. One variable was child weight. Weight was measured using a digital scale. Once the scale was placed on an even surface, each respondent would stand on it separately and the weight would be recorded by the interviewer or the interviewer's assistant. For infants who were unable to stand on the scale by themselves, an adult would hold the child after the adult's weight had been recorded. When having their weight measured, respondents were instructed to remove their shoes, sandals and heavy clothing. For younger children, all clothing with the exception of undergarments were removed. This measure was reported by DHS in hectograms but was converted to kilograms for this analysis.

The second variable that was evaluated was child bodymass-index (BMI). This variable was examined as a continuous variable by using the standard deviations of each child BMI from the mean child BMI, which was represented by zero. BMI was also categorized according to the WHO standards. Categories were as follows: underweight (-2 standard deviations from the mean), normal weight, and overweight (+2 standard deviations from the mean). Therefore in order to be considered underweight, a child would need to have a BMI z-score below 2 standard deviations (-2SD) of the median of the sample.

The independent variable was maternal reading level. In order to assess this literacy skill, interviewers asked patients to read a simple statement like "Farming is hard work." Four statements similar to this one would be displayed on a card in the language in which the respondent was most likely to be literate. If the participant was unable to read the statement, the interviewer would probe the respondent and ask if they could read any part of the sentence. Three categories were used for this variable: cannot read at all, able to read only parts of a sentence, and able to read whole sentence.

Finally, multiple control variables were included in the statistical models for this study. Control variables included weight of females of reproductive age (respondent weight), birth weight of child, respondent's highest year of education, wealth index, and region of residence (rural or urban). Wealth and maternal education have been shown to have a significant effect on both the independent and dependent variables used in the proposed relationship (Esposito, Kebede, \& Maddox, 2011; Makoka \& Masibo, 2015; Mallard et al., 2014).

\section{Statistical analysis}

Frequency tables were created for each categorical variable, including maternal reading level and maternity. A univariate procedure was performed in order to obtain descriptive statistics for the continuous variables of interest, such as child weight. The proposed relationship between maternal reading level and child weight was examined by performing analyses of covariance (ANCOVA). This procedure was used to determine whether significant differences existed in child weight and in child BMI based on the mother's reading level, controlling for other known predictors (i.e., respondent weight, birth weight of child, respondent's highest year of education, wealth index, and region of residence). The same procedures were performed for all children ages 0-47 months, as well as separately for each year of age being evaluated, to test whether maternal reading level had a greater effect on child weight at a specific age under 4. Missing values were excluded in the analysis of each variable. The software used for analysis was Statistical Analysis Software (SAS) version 9.4.

\section{RESULTS}

The majority of mothers from this sample could not read at all (58.69\%), a small number of mothers had partial literacy skills (7.67\%), and approximately one-third were completely literate (33.64\%). The majority of study subjects (83.36\%) were in the "normal” BMI category. The underweight BMI category consisted of 396 study subjects (6.06\%) [See Table 1]. 
Journal of the Georgia Public Health Association, Vol. 7, N 0. 2 [2019], Art. 16

Table 1. Child Anthropomorphic Measures by Age Group

\begin{tabular}{|c|c|c|c|c|}
\hline \multirow{2}{*}{ Age Group } & \multicolumn{3}{|c|}{ Body Mass Index Category } & Overweight \\
& Underweight & Normal Weight & (Kilograms) \\
\hline $\begin{array}{c}0-11 \text { months } \\
\text { Frequency }\end{array}$ & $81(7.37 \%)$ & $893(81.26 \%)$ & $125(11.37 \%)$ & 6.94 \\
\hline $\begin{array}{c}12-23 \text { months } \\
\text { Frequency }\end{array}$ & $115(7.40 \%)$ & $1256(8.77 \%)$ & $184(11.83 \%)$ & 9.59 \\
\hline $\begin{array}{c}24-35 \text { months } \\
\text { Frequency }\end{array}$ & $95(5.55 \%)$ & $1423(83.07 \%)$ & $195(11.38 \%)$ & 10.48 \\
\hline $\begin{array}{c}36-47 \text { months } \\
\text { Frequency }\end{array}$ & $98(5.72 \%)$ & $1444(84.35 \%)$ & $170(9.93 \%)$ & 10.41 \\
\hline $\begin{array}{c}\text { Total } \\
\text { Frequency }\end{array}$ & $396(6.05 \%)$ & $5447(83.36 \%)$ & $691(10.59 \%)$ & 9.99 \\
\hline
\end{tabular}

\section{Bivariate results}

A two-by-two frequency table of child BMI category by maternal literacy level demonstrated that the majority of children categorized as underweight (77.72\%) had mothers who had an absence of literacy skills. This table also showed that a mere $16.96 \%$ of underweight children had mothers who were completely literate [See Table 2].

Table 2. Child Body Mass Index Category by Maternal Literacy Level

\begin{tabular}{|l|c|c|c|c|}
\hline \multirow{2}{*}{$\begin{array}{l}\text { Child Body Mass Index } \\
\text { Category }\end{array}$} & \multicolumn{3}{|c|}{ Maternal Literacy Level } & \multirow{2}{*}{} \\
\cline { 2 - 5 } & $\begin{array}{c}\text { Cannot Read at } \\
\text { All }\end{array}$ & $\begin{array}{c}\text { Able to Read } \\
\text { Parts of a } \\
\text { Sentence }\end{array}$ & $\begin{array}{c}\text { Able to Read a } \\
\text { Whole Sentence }\end{array}$ & Total \\
\hline $\begin{array}{c}\text { Normal Weight } \\
\text { Frequency }\end{array}$ & $3171(58.30 \%)$ & $427(7.85 \%)$ & $1841(33.85 \%)$ & $5439(83.36 \%)$ \\
\hline $\begin{array}{c}\text { Overweight } \\
\text { Frequency }\end{array}$ & $389(56.30 \%)$ & $56(8.10 \%)$ & $246(35.60 \%)$ & $691(10.59 \%)$ \\
\hline $\begin{array}{c}\text { Underweight } \\
\text { Frequency }\end{array}$ & $307(77.72 \%)$ & $21(5.32 \%)$ & $67(16.96 \%)$ & $395(6.05 \%)$ \\
\hline $\begin{array}{c}\text { Total } \\
\text { Frequency } \\
\text { Average Weight }\end{array}$ & $3867(59.26 \%)$ & $504(7.72 \%)$ & $2154(33.01 \%)$ & 6525 \\
9.64 & 9.88 & 10.63 & 9.99 \\
\hline
\end{tabular}

\section{Covariance results}

Analysis of covariance (ANCOVA) tests were performed to determine differences in mean weight and standard deviation of BMI among children in each age group in reference to maternal literacy level. All ANCOVA models controlled for respondent weight, wealth index, birthweight, place of residence, and respondent's highest year of education.

There was a statistically significant ANCOVA results in mean weight between different levels of maternal literacy for children younger than one $(F[7,849]=2.90, p=0.005)$, one year-olds $(F[7,1107]=7.88, \mathrm{p}<.0001)$, two year-olds $(F[7,1159]=14.21, \mathrm{p}<.0001)$ and three yearolds $(F[7,1133]=25.08, \mathrm{p}<.0001)$. Post hoc analyses indicated significant differences in mean weight of one-, two-, and three-year olds with mothers who were illiterate and mothers who were completely literate. Significant mean differences in child weight were also indicated between mothers who have some literacy and mothers who are completely literate. There was also no significant difference in mean weight of child under the age of one, based on different literacy levels [See Table 3]. 
Table 3. Analysis of Covariance Results for the Effects of Maternal Literacy Level on Mean Differences in Child Weight by Age Group

\begin{tabular}{|c|c|c|c|c|c|c|}
\hline \multirow[b]{2}{*}{ Child Age Group } & \multirow[b]{2}{*}{ F-Value (df) } & \multirow[b]{2}{*}{ p-value } & \multicolumn{3}{|c|}{ Maternal Literacy Level } & \multirow[b]{2}{*}{ Post hoc } \\
\hline & & & $\begin{array}{l}\text { No Maternal } \\
\text { Literacy (1) } \\
\text { M }\end{array}$ & $\begin{array}{l}\text { Some Maternal } \\
\text { Literacy (2) } \\
\text { M }\end{array}$ & $\begin{array}{l}\text { Complete } \\
\text { Maternal Literacy } \\
\text { (3) } \\
\text { M }\end{array}$ & \\
\hline $\begin{array}{l}\text { 0-11 months } \\
\text { Weight } \\
\text { (kilograms) }\end{array}$ & $\begin{array}{l}2.90 \\
(7,849)\end{array}$ & 0.005 & 6.95 & 6.84 & 7.00 & $3=2=1$ \\
\hline $\begin{array}{l}\text { 12-23 months } \\
\text { Weight } \\
\text { (kilograms) }\end{array}$ & $\begin{array}{l}7.88 \\
(7,1107)\end{array}$ & $<.0001$ & 9.67 & 9.52 & 9.84 & $3>2,1$ \\
\hline $\begin{array}{l}\text { 24-35 months } \\
\text { Weight } \\
\text { (kilograms) }\end{array}$ & $\begin{array}{l}14.21 \\
(7,1159)\end{array}$ & $<.0001$ & 10.51 & 10.34 & 10.94 & $3>2,1$ \\
\hline $\begin{array}{l}\text { 36-47 months } \\
\text { Weight } \\
\text { (kilograms) }\end{array}$ & $\begin{array}{l}25.08 \\
(7,1133)\end{array}$ & $<.0001$ & 10.28 & 10.59 & 11.20 & $3>2,1$ \\
\hline
\end{tabular}

Note: $\mathrm{M}=$ Mean; $\mathrm{df}=$ Degrees of Freedom.

With regard to BMI, there was a statistically significant difference between levels of maternal literacy for children younger than one $(\mathrm{F}[7,779]=5.34, p<0.0001)$, one yearolds $(\mathrm{F}[7,1064)=2.73, p=0.008)$, two year-olds $(\mathrm{F}[7$, $1102]=4.87, p=<.0001)$ and three year-olds $(F[7,1072]=$
6.71, $p=<.0001$ ). Post hoc analyses indicated significant differences in mean BMI of children with mothers who were illiterate and mothers who were completely literate for all age groups. There was no significant difference between mothers with some literacy skills and other maternal literacy groups [See Table 4].

Table 4. Analysis of Covariance Results for the

Effects of Maternal Literacy Level on Mean Differences in Body-Mass-Index Age Group

\begin{tabular}{|c|c|c|c|c|c|c|}
\hline \multirow{3}{*}{$\begin{array}{l}\text { Child Age } \\
\text { Group }\end{array}$} & \multirow[b]{2}{*}{ F-Value (df) } & \multirow[b]{2}{*}{ p-value } & \multicolumn{3}{|c|}{ Maternal Literacy Level } & \multirow[b]{2}{*}{ Post hoc } \\
\hline & & & $\begin{array}{l}\text { No Maternal } \\
\text { Literacy (1) }\end{array}$ & $\begin{array}{l}\text { Some Maternal } \\
\text { Literacy (2) }\end{array}$ & $\begin{array}{c}\text { Complete Maternal } \\
\text { Literacy (3) }\end{array}$ & \\
\hline & & & M & M & M & \\
\hline 0-11 months & $\begin{array}{c}5.34 \\
(7,779)\end{array}$ & $<.0001$ & 0.17 & 0.11 & 0.25 & $3>1$ \\
\hline 12-23 months & $\begin{array}{c}2.73 \\
(7,1064)\end{array}$ & 0.0082 & 0.32 & 0.65 & 0.48 & $3>1$ \\
\hline 24-35 months & $\begin{array}{c}4.87 \\
(7,1102)\end{array}$ & $<.0001$ & 0.50 & 0.47 & 0.60 & $3>1$ \\
\hline
\end{tabular}




\begin{tabular}{|c|c|c|c|c|c|c|}
\hline \multirow{3}{*}{$\begin{array}{l}\text { Child Age } \\
\text { Group }\end{array}$} & \multirow[b]{2}{*}{ F-Value (df) } & \multirow[b]{2}{*}{ p-value } & \multicolumn{3}{|c|}{ Maternal Literacy Level } & \multirow[b]{2}{*}{ Post hoc } \\
\hline & & & $\begin{array}{l}\text { No Maternal } \\
\text { Literacy (1) }\end{array}$ & $\begin{array}{l}\text { Some Maternal } \\
\text { Literacy (2) }\end{array}$ & $\begin{array}{c}\text { Complete Maternal } \\
\text { Literacy (3) }\end{array}$ & \\
\hline & & & M & M & M & \\
\hline 36-47 months & $\begin{array}{c}6.71 \\
(7,1072)\end{array}$ & $<.0001$ & 0.20 & 0.41 & 0.48 & $3>1$ \\
\hline
\end{tabular}

Note: $\mathrm{M}=$ Mean; $\mathrm{df}=$ Degrees of Freedom.

\section{DISCUSSION}

The purpose of this study was to examine the possible effects of maternal literacy level on child weight and BMI. It was hypothesized that maternal literacy level would affect the weight and BMI of children ages 0-3, which was partially supported. Specifically, maternal literacy level was significantly associated with both child weight and BMI; however, differences in these associations emerged according to child age. This suggests that the relationship needs to be further investigated, as well as the importance of child age in the proposed relationship.

Findings demonstrated an increase of effect for each year of age, indicating a more significant effect in older children. Since the need for dietary diversity has already been identified in previous research, it can be inferred that this increase in effect results from the need for dietary variation as the child grows (Mallard et al., 2014; Wachs, 2008). Also, significant mean differences in weight were identified between all levels of maternal literacy. This supports the idea that even small increases in literary skills can have a positive effect on child weight. However, this will need to be tested in the future using more rigorous research methods.

Interestingly, there was no difference in mean weight based on maternal literacy level for children ages 0-11 months. The similarity in means for this age group may be the result of greater variability in weight within literacy levels among younger children. Increased variability could be the result of the large sample size of this study; an effect could have been more difficult to detect because of this variability. This lack of effect due to variability was also observed for BMI between the group of mothers with some literacy skills and other maternal literacy groups.

The results also support the proposed relationship between maternal reading level and child BMI. As seen with child weight, the effects of maternal literacy on child BMI also increased with each year of age. This further supports the hypothesis that the effects of maternal literacy level are more significant as the child gets older. However, the associations for BMI were much smaller than those for child weight. This could suggest that maternal literacy rate has a significant, but weak, effect on child height as compared to child weight. This finding could help expound on previous research by comparing the effects of maternal literacy rate on weight and its effects on height (Burchi, 2010; Burchi, 2012).

Compared to BMI, we observed greater differences in weight based on maternal reading level. The measure of BMI was used for this study because it provides a more complete picture of child health by incorporating height, weight and standards by age. However, it did not allow us to investigate height and weight separately. Since the effect of maternal literacy level was less significant for BMI, it will be important to examine the effect of maternal reading level on height.

\section{Study strengths and limitations}

The major strength of this study was the large sample size from a low-resource country. This can provide a more representative depiction of the population and can decrease variability in the sample. Another strength of the study was the novel approach that was taken by focusing on maternal literacy rate, as well as the use of BMI for children under the age of 5. Very few studies have investigated maternal reading level as a predictor variable for child anthropomorphic measures and none have examined the possible association between maternal literacy rate and child weight. Also, this study used the BMI standard deviation measure, which was developed as part of the new WHO Child Growth Standards (World Health Organization, 2016).

In terms of study limitations, the study sample did not accurately represent the Mozambican population, despite being relatively large. The percentage of underweight children in Mozambique in 2011 was reported to be as high as sixteen percent (World Health Organization, 2011). However, the percentage of underweight children in the study sample was approximately six percent. This was possibly due to the exclusion of children with missing weight data and children whose mothers had missing literacy rate data. Even though data was collected by household, family data were not reported together. This 
meant that a mother's data could not be linked to that of her specific child in the analysis. Another limitation of the study was the use of respondent measures rather than maternal measures. Covariates in the ANCOVA model included respondent weight and respondent's highest year of education. In future studies, subsetting these variables to be specific to mothers will provide a more accurate depiction of the effect of maternal characteristics on child weight. Also, the measure of maternal reading level was limited. In future studies, a more thorough test of both reading and writing should be utilized to accurately assess maternal literacy level. Maternal nutrition knowledge should also be assessed.

\section{CONCLUSIONS}

This study was an important first step in explicating the associations among maternal literacy and child weight. The findings inform future directions in research. These include the investigation of the effect of maternal literacy on child weight in other countries, as well as a deeper understanding of the interaction between weight and socioeconomic status. Weight and wealth were found to be significantly correlated in the current study. It is likely that these two variables are connected by nutrition. A lack of financial resources could lead to lower nutritional education for various reasons, such as dropping out of school in order to provide additional income. However, a more direct consequence could result from the purchase of inexpensive foods with little to no nutritional value. It is possible that increased literacy level could aid mothers in healthy food selection, even with limited financial resources. Therefore, future studies should assess whether increased maternal reading level can offset the effect of low socioeconomic status.

Furthermore, study findings would be further advanced by the inclusion of additional variables including observational measures that will allow for a more accurate assessment of maternal literacy. Additionally, child feeding practices, like breastfeeding, should also be included in future studies. These practices can influence child nutrition and weight, which would also influence the relationship between maternal literacy and child weight.

Researchers should also investigate the potential effects of the father's reading level on child weight. Since Mozambican men have higher literacy rates and more completed formal education than Mozambican women, it is possible that the education and literacy of a father could balance out the negative effects of a mother's lack of literacy skills (Burchi, 2012; Central Intelligence Agency, 2014).

Future studies should include child nutrition information in order to further investigate the maternal literacy-child weight relationship. Since nutritional status has a direct effect on a child's weight, it would be interesting to explore the potential effect of maternal literacy on nutrition. If a mother's reading level is significantly correlated with child nutrition, a pathway explaining the maternal literacy-child weight relationship could be developed. This pathway would propose that low maternal literacy level leads to a lack of nutrition knowledge and, subsequently, a nutritionpoor diet and lower weight in children. Additionally, access to nutrition and health information should also be taken into consideration. With less than one physician for every 1,000 people in Mozambique, many mothers are not able to consult with a healthcare provider about their child's nutritional needs (Central Intelligence Agency, 2014). Similarly, there are many areas of the United States where individuals may lack access to physicians. For instance, in the state of Georgia, there were 2.25 active physicians per 1,000 people in 2016 (Association of American Medical Colleges, 2017). In fact, in rural areas of Georgia, the lack of access to healthcare mirrors that of Mozambique. Policies need to be created to increase female education so that mothers can gain the skills necessary to access nutritional information. Additional policies and incentives should be developed to assist in creating sustainable plans that will increase both the number of various healthcare providers, such as doulas, midwives, and nurses who can train parents on child nutrition, as well as to ensure that these individuals are accessible to all new mothers.

\section{Acknowledgements \\ I would like to thank the members of my thesis committee, particularly Dr. Shannon-Self-Brown, for their continued patience and support. I would also like to acknowledge Melissa Cowart- Osbourne, Jessica Rogers Brown, and Rachel Hopper for their contribution to the statistical analysis of this project.}

Statement of Student-Mentor Relationship: The lead author for this report, Ashley Watson, a Master of Public Health student, completed the Master of Public Health Program at Georgia State University in 2016. Dr. Shannon Self-Brown, the senior author, served as her mentor and thesis chair.

\section{References}

Association of American Medical Colleges. (2017). Georgia Physician Workforce Profile. Retrieved June 12, 2018 from

https://www.aamc.org/download/484530/data/georgiaprofile.pdf

Burchi, F. (2010). Child nutrition in Mozambique in 2003: The role of mother's schooling and nutrition knowledge. Economics and Human Biology, 8331-345. doi:10.1016/j.ehb.2010.05.010

Burchi, F. (2012). Whose education affects a child's nutritional status? From parents' to household's education. Demographic Research, 27, 681-704. doi: 10.4054/DemRes.2012.27.23

Centers for Disease Control. (2015, May 15). About Child \& Teen BMI. Retrieved April 09, 2016, from

http://www.cdc.gov/healthyweight/assessing/bmi/childrens_bmi/ about_childrens_bmi.html

Central Intelligence Agency. (2014). The World Factbook: Mozambique. Retrieved January 6, 2016, from

https://www.cia.gov/library/publications/the-worldfactbook/geos/mz.html

Esposito, L., Kebede, B., \& Maddox, B. (2011). Literacy Practices and Schooling: A Case Study from Mozambique. World Development, 391796-1807. doi:10.1016/j.worlddev.2011.04.011

Hassinger-Das, B., Jordan, N. C., \& Dyson, N. (2015). Reading Stories to Learn Math: Mathematics Vocabulary Instruction for Children with Early Numeracy Difficulties. The Elementary School Journal, 116(2), 242-246.

InstitutoNacional de Estatística, Ministério da Saúde [Mozambique] and Macro International Inc. Mozambique Demographic and Health Survey 2011 [Dataset]. Data Extract 
from MZIR41.SAV and MZHR41.SAV. Integrated

Demographic and Health Series (IDHS), version 1.0, Minnesota Population Center and ICF International [Distributors]. Accessed from http://idhsdata.org on September 10, 2015.

Julius, M. S., Meir, R., Shechter-Nissim, Z., \& Adi-Japha, E. (2016). Children's ability to learn a motor skill is related to handwriting and reading proficiency. Learning and Individual Differences, 51265-272. doi:10.1016/j.lindif.2016.08.034

Makoka, D. \& Masibo, P. K. (2015). Is there a threshold level of maternal education sufficient to reduce child undernutrition? Evidence from Malawi, Tanzania and Zimbabwe. BMC Pediatrics, 15(1), 96.doi:10.1186/s12887-015-0406-8

Mallard, S. R., Houghton, L. A., Filteau, S., Mullen, A., Nieuwelink, J., Chisenga, M., \& ... Gibson, R. S. (2014). Dietary Diversity at 6 Months of Age Is Associated with Subsequent Growth and Mediates the Effect of Maternal Education on Infant Growth in Urban Zambia. Journal of Nutrition, 144(11), 18181825. doi:10.3945/jn.114.199547

Matijasevich, A., Howe, L. D., Tilling, K., Santos, I. S., Barros, A. D., \& Lawlor, D. A. (2012). Maternal education inequalities in height growth rates in early childhood: 2004 Pelotas birth cohort study. Paediatric and Perinatal Epidemiology, 26(3), 236-249. doi:10.1111/j.1365-3016.2011.01251.x

McLeroy, K. R., Bibeau, D., Steckler, A., \& Glanz, K. (1988). An Ecological Perspective on Health Promotion Programs. Health Education \& Behavior, 15(4), 351. doi:10.1177/109019818801500401

Rajalakshmi, L., Zhang, J., Zhang, J., Koch, F. S., Marcus, C., Ludvigsson, J., \& ... Sobko, T. (2013). Higher maternal education is associated with favourable growth of young children in different countries. Journal of Epidemiology \& Community Health, 67(7), 595-602. doi:10.1136/jech-2012202021

Saleem, A. F., Mahmud, S., Baig-Ansari, N., \& Zaidi, A. M. (2014). Impact of Maternal Education about Complementary Feeding on Their Infants' Nutritional Outcomes in Low- and Middle-income Households: A Community-based Randomized Interventional Study in Karachi, Pakistan. Journal of Health, Population \& Nutrition, 32(4), 623-633.

Sufiyan, M. B., Bashir, S. S., \& Umar, A. A. (2012). Effect of maternal literacy on nutritional status of children under 5 years of age in the Babban-Dodo community Zaria city, Northwest Nigeria. Annals of Nigerian Medicine, 6(2), 61-64. doi:10.4103/0331-3131.108110

The Demographic and Health Surveys (DHS) Program. (n.d.). Protecting the Privacy of DHS Survey Respondents. Retrieved June 12, 2018, from https://www.dhsprogram.com/What-WeDo/Protecting-the-Privacy-of-DHS-Survey-Respondents.cfm

UNICEF (2013). Mozambique: Statistics. Retrieved April 03, 2016, from http://www.unicef.org/infobycountry/mozambique_statistics.ht $\mathrm{ml}$

Vesel, L., Bahl, R., Martines, J., Penny, M., Bhandari, N., \& Kirkwood, B. R. (2010). Use of new World Health Organization child growth standards to assess how infant malnutrition relates to breastfeeding and mortality. Bulletin of the World Health Organization, 88(1), 39-48.

Wachs, T. D. (2008). Multiple influences on children's nutritional deficiencies: A systems perspective. Physiology \& Behavior, 94(Purdue University Ingestive Behavior Research Center Symposium. Influences on Eating and Body Weight over the Lifespan: Childhood and Adolescence), 48-60. doi:10.1016/j.physbeh.2007.11.018

Wolde, M., Berhan, Y., \&Chala, A. (2015). Determinants of underweight, stunting and wasting among schoolchildren. BMC Public Health, 15(1), 93-110. doi:10.1186/s12889-014-1337-2

World Bank. (2013). World databank.[Custom cross-tabulation of data]. Retrieved from http://data.worldbank.org/indicator/SP.DYN.IMRT.IN

World Health Organization. (2011). Mozambique. Retrieved January 6, 2016, from http://www.who.int/countries/moz/en/

World Health Organization. (2015). Indicator and Measurement Registry version 1.7.0. Retrieved February 17, 2016, from http://apps.who.int/gho/indicatorregistry/App_Main/indicator_re gistry.aspx

World Health Organization. (2016). Child Growth Standards. Retrieved April 10, 2016, from http://www.who.int/childgrowth/en/

Young-Loveridge, J. M. (2004). Effects on Early Numeracy of a Program Using Number Books and Games. Early Childhood Research Quarterly, 19(1), 82-98.

(c) Ashley Watson, Shannon Self-Brown, Iris Feinberg, and Whitney Rostad. Originally published in jGPHA (http://www.gapha.org/jgpha/) October 25, 2019. This is an open-access article distributed under the terms of the Creative Commons Attribution Non-Commercial NoDerivatives License (http://creativecommons.org/licenses/by/4.0/), which permits unrestricted use, distribution, and reproduction in any medium, provided the original work ("first published in the Journal of the Georgia Public Health Association...") is properly cited with original URL and bibliographic citation information. The complete bibliographic information, a link to the original publication on http://www.gapha.jgpha.org/, as well as this copyright and license information must be included. 